\title{
Characterization of Tomatoes Expressing Anthocyanin in the Fruit
}

\author{
Peter J. Mes ${ }^{1}$, Peter Boches, and James R. Myers ${ }^{2}$ \\ Department of Horticulture, ALS 4137, Oregon State University, Corvallis, OR 97331 \\ Robert Durst \\ Department of Food Science and Technology, Oregon State University, Corvallis, OR 97331
}

\begin{abstract}
AdDitional INDEX words. flavonoids, phenolics, carotenoids, Solanum lycopersicum
Abstract. Cultivated tomatoes (Solanum lycopersicum L.) produce anthocyanins in vegetative tissues and certain flavonols can be found in the fruit. Some related wild species do produce anthocyanins in the fruit, and this trait has been transferred into cultivated tomato. Fruit with the genes $A b g, A f t$, and atv exhibit varying degrees of anthocyanin production in the epidermis, but not in the fruit pericarp. Fruit with these alleles in various combinations were analyzed to characterize the anthocyanidin profile, moieties, and total anthocyanin content. In general, combining atv with either $A f t$ or $A b g$ substantially increased anthocyanin production in the fruit. Over 23 different anthocyanins were detected, petunidin-3-(p-coumaryl)-rutinoside-5-glucoside being predominant. The highest level of anthocyanin expression was observed in small fruit with the genotype Abg-atvatv and AftAft atvatv, well in excess of $100 \mathrm{mg} / 100 \mathrm{~g}$ fresh weight of epidermis and subepidermis depending on the size of the fruit. Nonanthocyanin flavonoids were also upregulated in proportion to the anthocyanin concentration. The anthocyanin genes were also combined with genes affecting carotenoid composition and content. Reduced carotenoid content conditioned by the alleles $B$ (Beta) and $r$ (yellow flesh) was associated with lower total anthocyanins, an unexpected observation because the carotenoid and anthocyanin pathways are thought to be independent. The level of anthocyanin did not affect carotenoid profiles or amounts.
\end{abstract}

Tomato fruit vary in size, shape, and pigmentation with typical colors ranging from white, pink, red, orange, yellow, and green. "Black" or "purple" is a name often applied to heirloom varieties exhibiting a pink, brown, or dark green fruit color. These colors come about from interactions of the carotenoid-based pericarp color (controlled by several genes), presence or absence of color in the epidermis (gene symbol $y$ ), and presence or absence of the green shoulder trait $(u)$ and the green flesh ( $g f$ ) gene (Butler, 1962; Jones, 2000). Green flesh prevents normal chlorophyll breakdown resulting in the brown pigment, pheophytin, which, when combined with the red of lycopene, produces, as first described by Kerr (1956), a "dirty purplish brown" color.

The pigments in most fruit and vegetables with purple color are anthocyanins, but to our knowledge, none of the so-called purple or black tomatoes contain substantial quantities of anthocyanins. The cultivated tomato does express anthocyanins in vegetative tissues. Some wild tomato relatives do have anthocyanin-pigmented skin, and this trait has been transferred into cultivated tomato (Georgiev, 1972; Rick, 1964; Rick et al., 1994).

Production of anthocyanins in fruit of cultivated tomatoes was first reported by Georgiev (1972) after introgression from Solanum chilense Dunal. Phenotypically, anthocyanins are expressed in the subepidermal tissue in green and ripe fruit stages resulting in a "purple" skin color. The dominant allele $A f$

Received for publication 14 May 2007. Accepted for publication 4 Jan. 2008. Research supported by the Baggett-Frazier Vegetable Breeding and Genetics Endowment, and Campbell Soup Co.

Presented at the Tomato Round Table meetings at Annapolis, MD, in 2004, and the American Society of Horticultural Science meetings in Austin, TX, in 2004.

${ }^{1}$ Current address: 2353 Eastbrooke Rd., Twin Falls, ID 83301.

${ }^{2}$ Corresponding author. E-mail: myersja@hort.oregonstate.edu. was described by Georgiev and later renamed by Jones (2000) to $A f t$ to prevent confusion with anthocyanin free gene af (Jones et al., 2003). It initiates anthocyanin expression in immature green fruit with continued accumulation throughout development. Epidermal cells located outside the placental septa first express pigment, but with time, pigmentation spreads uniformly across the fruit where it is exposed to sufficient light levels. Recent research suggests that $A f t$ is an allele of the AN2 locus on chromosome 10 (Boches and Myers, 2007; DeJong et al., 2004).

A second gene causing anthocyanin production in fruit is Aubergine (Abg), as described by Rick et al. (1994). Abg was introgressed into tomato from Solanum lycopersicoides Dunal accession LA2408 and has been mapped to chromosome 10 of cultivated tomato. It is not known whether $A b g$ resides at the same locus as $A f t$, but it is located on the same chromosome arm. In crosses with cultivated tomato, S. lycopersicoides shows a paracentric inversion for this arm of chromosome 10 (Canady et al., 2006), which has prevented stable introgression and study of the trait in S. lycopersicum. Abg is phenotypically similar to $A f t$ in requiring high light intensity to induce anthocyanin expression. Unlike $A f t, A b g$ has variegated expression. A blotchy, flecked appearance or a solid, intensely pigmented sheet at maturity may be observed on fruit of the same plant so long as the fruit receive at least partial or even indirect light exposure. $A b g$ can show some of the most intense pigment expression of the tomato anthocyanin mutants, leading to the name Aubergine, a reference to the purple color found in the skin of eggplant (Solanum melongena L.) fruit.

The gene atroviolaceum (atv) in tomato influences anthocyanin accumulation in the entire plant. This gene was originally found in Solanum cheesmaniae (L. Riley) Fosberg, where it causes purple pigmentation in foliage and fruit, and has been located to chromosome 7 of tomato (Rick et al., 1968). Whereas 
the anthocyanin pigmented fruit characteristic is found almost exclusively in the green-fruited Solanum clade, S. cheesmaniae is an exception in that it belongs to the red- to yellow-colored fruit Solanum clade. When transferred into cultivated tomato (Rick, 1964), the purple fruit phenotype was only weakly expressed. In contrast to $A f t$ and $A b g$, atv is reported to condition recessive inheritance, although we have actually found an additive response (Rick et al., 1968; unpublished data).

The atv gene regulates the phytochrome response (Kerckhoffs et al., 1997); $A f t$ and $A b g$ have not been characterized, thus it is unknown the pathway in which they may interact, and it is possible that they all act within the same pathway but are tissue-specific. For example, unlike atv, neither Aft nor $A b g$ produces an elevated anthocyanin response in vegetative plant tissues, but they all produce the same anthocyanidin in their respective target tissues. Aft does have characteristics typical of a high-photoperiod response mutant, including elevated carotenoid content (Jones, 2000), evidence that it may regulate the phytochrome pathway. Aft and $A b g$ produce an anthocyanin response in the cell layer directly beneath the epidermis. The intensity and timing of the response varies among the two genes, although they share the property that no other tissue layers are affected, although other layers of leaf, stem, and fruit tissue have the capacity for plastid development (Kendrick et al., 1994).

Anthocyanins are the result of the flavonoid pathway, which also produces flavonoids and flavonols at higher points in the pathway. Regulation of the pathway is tissue- and developmental-specific. The flavonoid naringenin chalcone and flavonols quercetin-glycosides and kaempferol-glycosides accumulate almost exclusively in the peel during fruit ripening (Krause and Galensa, 1992; Muir et al., 2001). Analysis of enzyme transcripts in tomatoes without $A b g, A f t$, or atv revealed that chalcone synthase (chs), chalcone isomerase (chi), and flavonols synthase $(f l s)$ are below detection levels in fruit pericarp, whereas in the peel, chs, flavonoid-3 hydroxlyase ( $3 h$ ), and $f l s$ are expressed in abundance (Verhoeyen et al., 2002). For anthocyanins to be produced, the enzyme anthocyanin synthase (ans) must be expressed in conjunction with other enzymes that stabilize and modify the anthocyanin structure and composition. Abg and $A f t$ appear to be regulatory genes that upregulate the flavonoid pathway, including ans, to produce anthocyanins (Boches and Myers, 2007; Mes, 2005).

Anthocyanins in tomato vegetative tissues have been previously characterized by Ibrahim et al. (1968) and are composed mainly of petunidin, malvidin, and delphinidin. Jones et al. (2003) further determined that the anthocyanidins produced in Aft fruit were similar in composition and quantity to those from vegetative tissues. Further characterization of anthocyanin composition of other anthocyanin-affecting tomato fruit genes is needed.

In the present work, we discuss the interactions of $A b g$ and $A f t$ with atv for pigment intensity and composition. In addition, we combined the anthocyanin genes with high pigment 1 ( $\mathrm{hp}$ 1 ), encoding a nonfunctioning DNA damage-binding protein 1 (Liu et al., 2004), which results in the upregulation of the phytochrome responses, including flavonoids and carotenoids, to examine the effect of these gene combinations on fruit anthocyanin expression and anthocyanin profile. The anthocyanin genes were also combined with genes affecting carotenoid content to observe changes in anthocyanin expression in different carotenoid backgrounds.

\section{Materials and Methods}

SourCe OF GERMPLASM. LA3668 (Abg), LA1996 (Aft), LA0797 and LA3736 (atv), LA3538 ( $h p-1)$, LA3311 $\left(\operatorname{og}^{c}\right)$, LA3532 $(r)$, LA3183 $(t)$, and LA2374 $(B)$ were acquired from the C.M. Rick Tomato Genetic Resources Center, University of California, Davis. 'Caro Rich', possessing B, was acquired from Seeds of Change, Santa Fe, NM. The genetic stocks were highly inbred in an 'Ailsa Craig' background, with the exception of LA3668, in which $A b g$ was maintained only in the heterozygous state in 'VF 36' background, LA0797 (atv) also in 'VF 36', and LA1996 (Aft) maintained in an undeclared background.

Plant hybridization. Plants of the desired genotype were crossed in the greenhouse with generation advance occurring in the field and greenhouse. Standard emasculation and hand crosspollination procedures were used (Rick, 1980).

Parental combinations and generation advance are shown in Figure 1. In 2002, pairwise crosses of LA3736 (atv) $\times$ LA1996 $($ Aft $)$ and LA3736 (atv) $\times$ LA3668 (Abg) were made, followed by generation advance to the $\mathrm{F}_{2}$ where the most extreme phenotypes were selected. Aft atv and $A b g$ atv lines were selected from the $\mathrm{F}_{3}$ generations for crossing to produce putative triple mutant lines. The combination of $A f t$ with $h p-1$ was produced from the cross LA1996 $(A f t) \times$ LA3538 $(h p-1)$ with selection for high pigment type and anthocyanin beginning in the $\mathrm{F}_{2}$ and carried to the $\mathrm{F}_{6}$ generation. An Aft-atvatv double mutant line with "normal" red color from typical lycopene and $\beta$-carotene expression was crossed to the orange LA2374 (B) and yellow LA3532 $(r)$ tomato accessions and advanced to the $\mathrm{F}_{2}$ generation by Summer 2004. No segregants were observed carrying both the $B$ gene and the homozygous recessive condition of atv, so the effects of homozygous-recessive atvatv in combination with $B$ and $A f t$ were not available for study.

Plant growth AND Production. Tomato seeds were sown in Sunshine SB-40 professional growing mix (Sun Gro Horticulture, Bellevue, WA) in 5-cm-diameter plastic transplant cells. After emergence, the seedlings were watered once with 20N-8.7P-16.6K fertilizer solution (Peters 20-20-20; Scotts Miracle Grow Co., Marysville, $\mathrm{OH}$ ) and given tap water thereafter as needed. Seedlings were transplanted into $3.8-\mathrm{L}$ pots filled with SB-40 potting mix and $15 \mathrm{~g}$ of $14 \mathrm{~N}-6.1 \mathrm{P}-11.6 \mathrm{~K}$ slow-release fertilizer (Osmocote Classic 14-14-14; Scotts Miracle Grow Co.) after 3 weeks. Plants were given $15 \mathrm{~g}$ of supplemental Osmocote after 4 weeks in the pots. Greenhouse

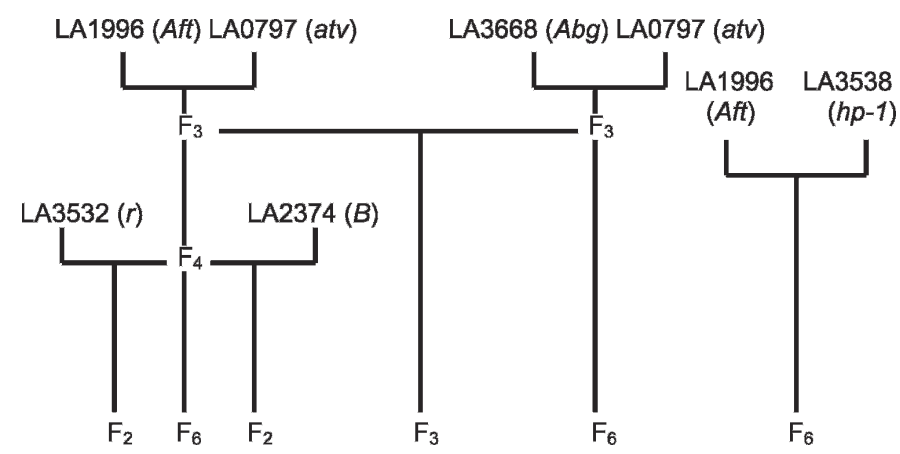

Fig. 1. Crossing scheme used to develop the Oregon State University lines used in the present study of anthocyanin expression in tomato fruit. Final generation is that as of Summer 2004. 
temperature was set to $18^{\circ} \mathrm{C}$ night and $25^{\circ} \mathrm{C}$ day. Supplemental lighting during the winter and spring seasons was provided by six 400-W metal halide and six 400-W high-pressure sodium Sun System 3 high-intensity discharge lamps (Sunlight Supply, Woodland, WA). Generation advance and fruit for nutrient analysis were produced at the Oregon State University Vegetable Farm, Corvallis on a Chehalis silt loam river bottom soil. Transplants used for field production were started in the greenhouse as described previously and then transplanted to the field after $\approx 8$ weeks during the third or fourth week of May. They were planted at $1-\mathrm{m}$ spacing within rows and with $1.3-\mathrm{m}$ between rows. Plots received $505 \mathrm{~kg} \cdot \mathrm{ha}^{-1}$ of $12 \mathrm{~N}-12.6 \mathrm{P}-8.3 \mathrm{~K}-$ $1.6 \mathrm{~S}$ fertilizer banded before planting. Water was applied through solid set sprinkler irrigation every 7 to $14 \mathrm{~d}$ as needed until most plants had abundant fruit set. Water was withheld from approximately the third week in August. Plots were maintained using standard cultural practices for fresh market production with application of copper hydroxide fungicide (Kocide; Griffin L.L.C. Valdosta, GA) at label rates late in the growing season when climatic conditions favored development of late blight [Phytothora infestans (Mont.) de Bary].

Anthocyanin EXtraction and PURIFICATION. Fruit were harvested from the field by hand at maturity and were either processed the same day or were placed in $-23{ }^{\circ} \mathrm{C}$ cold storage for later analysis. Mature fruit were selected by visual observation of the fruit blossom end, where carotenoid development is usually not obscured from view by anthocyanin in the skin. When carotenoid color was observed at the blossom end, fruit were considered mature. Fully ripe fruit were frozen at $-23{ }^{\circ} \mathrm{C}$ according to protocol and stored until anthocyanin extraction. Anthocyanins were extracted from the tomato skins using the Basic Protocol 1 of Rodriguez-Saona and Wrolstad (2001). Fruit were removed from the freezer and immersed in $50{ }^{\circ} \mathrm{C}$ water for $\approx 10 \mathrm{~s}$ to cause the skin to pull away from the pericarp, allowing for complete and clean skin removal. The skin was quickly removed, blotted dry, weighed, and placed in liquid nitrogen for immediate cryogenic milling. Replicates (different fruit from the same plant) were extracted using $\approx 20$ g of cryogenically milled tomato peel and were volumetrically adjusted. After isolating the anthocyanins in acidified water, the samples were purified by passage through a $\mathrm{C}_{18}$ solidphase Sep-Pak minicolumn (Waters, Milford, MA) to remove sugars and acids using Basic Protocol 2 of Rodriguez-Saona and Wrolstad (2001). The ethyl acetate and methanol rinses of the separatory column were collected, dried, and resolubilized in acidified water for future analysis.

For the samples analyzed in 2006 (Table 1), anthocyanins were extracted in acidified methanol using a microprep method. Briefly, $\approx 100 \mathrm{mg}$ of pigmented tissue was ground into a fine powder with liquid nitrogen and extracted over- night in $300 \mu \mathrm{L}$ of $1 \% \mathrm{HCl}$ methanol at $5{ }^{\circ} \mathrm{C}$. The extraction volume was brought to $500 \mu \mathrm{L}$ with nanopure water and $500 \mu \mathrm{L}$ of chloroform was added to the tube. The tubes were centrifuged for $5 \mathrm{~min}$ at $2400 \mathrm{~g}_{\mathrm{n}}$ and the aqueous phase was removed to a new tube.

ANTHOCYANIN SPECTROPHOTOMETRY AND HIGH-PERFORMANCE LIQUID CHROMATOGRAPHY ANALYSIS. A subsample of the purified methanol fraction was analyzed by a Shimadzu ultravioletvisible (ultraviolet-vis) recording spectrophotometer UV160A (illuminant C) (Shimadzu, Kyoto, Japan) to determine the anthocyanin spectral absorption by transmission. The sample was diluted by $50 \%$, placed in a quartz cuvette, and analyzed by spectrophotometer from $250 \mathrm{~nm}$ to $800 \mathrm{~nm}$. Sample hydrolysis was accomplished using the Basic Protocol 1 of Durst and Wrolstad (2001) to determine the anthocyanidins and were saponified using the Basic Protocol 3. The high-performance liquid chromatography (HPLC) protocol was used as reported by Durst and Wrolstad (2001) with slight modification: Solvent A was acetonitrile, and Solvent B consisted of $10 \%$ acetic acid and $1 \%$ phosphoric acid in water. Chromatographic conditions were initially $2 \% \mathrm{~A}, 98 \% \mathrm{~B}$, with a linear gradient over $25 \mathrm{~min}$ to $20 \% \mathrm{~A}, 80 \% \mathrm{~B}$, a $10-\mathrm{min}$ gradient to $40 \% \mathrm{~A}, 60 \% \mathrm{~B}$, and a 2-min hold at $40 \% \mathrm{~A}, 60 \% \mathrm{~B}$ before returning to the start conditions at a flow rate of $1 \mathrm{~mL} \cdot \mathrm{min}-1$. Simultaneous detection at 280,320, and $520 \mathrm{~nm}$ was recorded using a Hewlett-Packard 1090 photodiode array detector (Agilent Technologies, Wilmington, DE). Twenty-microliter samples were injected into this system that was equipped with a Prodigy $5 \mu \mathrm{m}$ ODS $(3 \mu \mathrm{m})$ $10 \mathrm{~nm}(250 \times 4.6 \mathrm{~mm})$ column fitted with a $4.0 \times 3.0 \mathrm{~mm}$ i.d. guard column (Phenomex, Torrance, CA).

Anthocyanin mass SPectroscopy. Samples were analyzed by HPLC-mass spectroscopy (MS) to determine the number of anthocyanin groups and their respective masses. HPLC-MS data were produced using a using a Hewlett-Packard 1090
Table 1. Total monomeric anthocyanin content in tomato fruit grown at the Vegetable Farm in Corvallis, OR, in 2004 and 2006.

\begin{tabular}{|c|c|c|c|}
\hline Cross & Genotype & Fruit wt (g) & $\begin{array}{l}\text { Total anthocyanins } \\
(\mathrm{mg} / 100 \mathrm{~g} \mathrm{FW} \text { skin })^{\mathrm{z}}\end{array}$ \\
\hline \multicolumn{4}{|l|}{$2004^{y}$} \\
\hline LA1996 & AftAft & 115.23 & $72.32 \mathrm{~d}$ \\
\hline LA1996 × LA2374 & Aft-B- & 124.37 & $23.77 \mathrm{e}$ \\
\hline LA1996 × LA3538 & Aft- $h p-1 h p-1$ & 162.37 & $89.14 \mathrm{c}$ \\
\hline LA1996 × LA0797 & AftAft atvatv & 87.60 & $116.11 \mathrm{~b}$ \\
\hline LA1996 × LA0797 × LA3532 & Aft-atvatv $r r$ & 62.83 & $17.86 \mathrm{e}$ \\
\hline LA3668 × LA0797 & Abg-atvatv & 37.18 & $414.97 \mathrm{a}$ \\
\hline LA3532 & $r r$ & 51.36 & $0.00 \mathrm{f}$ \\
\hline \multicolumn{4}{|l|}{2006} \\
\hline$P 20-3^{x}$ & AftAft atvatv & 59.30 & $110.79 \mathrm{a}$ \\
\hline LA1996 (no. 2) & AftAft & 93.37 & $36.35 \mathrm{~b}$ \\
\hline LA3668-3-2 & Abg- & 35.72 & $19.21 \mathrm{c}$ \\
\hline LA1996 (no. 1) & AftAft & 95.70 & $17.68 \mathrm{dc}$ \\
\hline LA0797 & atv atv & 46.97 & $12.10 \mathrm{cde}$ \\
\hline LA3736 & atv atv & 41.22 & 7.79 def \\
\hline Legend & - & 66.75 & $0.00 \mathrm{f}$ \\
\hline
\end{tabular}

${ }^{\mathrm{z}}$ Means followed by the same letter within years are not significantly different $P \leq 0.05$ as determined by Fisher's protected least significant difference.

${ }^{\mathrm{y}}$ Mean of three replicate $\mathrm{pH}$ differential tests \pm SD for 2004; mean of three fruit from a single plot in 2006.

${ }^{\mathrm{x}}(\mathrm{LA} 1996 \times \mathrm{LA} 0797) \times(\mathrm{LA} 3736 \times$ LA3668 $)$.

$\mathrm{FW}=$ fresh weight. 
photodiode array detector (Agilent Technologies) and a PerkinElmer SCIEX API III triple-quadrupole mass spectrometer (Perkin-Elmer, Toronto, Ontario, Canada) equipped with an ion spray source $(\mathrm{ISV}=5500$, orifice voltage $=50)$ in positive ion mode. Multiple reaction monitoring mode was used, scanning the mass of the molecular (parent) ions in the first quadrupole (Q1) and scanning for the fragmented ions and anthocyanidins (daughter ions) in the third quadrupole (Q3). Argon was used as the collision gas, and nitrogen was used for the nebulizer gas and orifice curtain. The system was equipped with a Synergi $4 \mu$ Hydro-RP $80 \AA$ ( $(250 \times 2 \mathrm{~mm})$ column fitted with a $4.0 \times 3.0 \mathrm{~mm}$ i.d. guard column (Phenomex). Solvent A was 5\% formic acid, $80 \%$ acetonitrile $(\mathrm{v}: \mathrm{v})$; solvent $\mathrm{B}$ contained 5\% formic acid. Chromatographic conditions were initially $10 \%$ A, $90 \%$ B, with a linear gradient $30 \% \mathrm{~A}, 70 \% \mathrm{~B}$ in $30 \mathrm{~min}$, using a $0.2 \mathrm{~mL} \cdot \mathrm{min}^{-1}$ flow rate. Twenty-microliter samples were injected into this system.

Anthocyanin QUANTIFication by PH Differential. Monomeric anthocyanin content was measured in 2004 field-grown fruit using the $\mathrm{pH}$ differential method (Guisti and Wrolstad, 2001) from the ethyl acetate and methanol fractions produced in the anthocyanin extraction procedure. Replicate anthocyanin extracts were diluted 10 -fold in $\mathrm{pH} 1$ and $\mathrm{pH} 4.5$ buffers, allowed to stand for $10 \mathrm{~min}$, and scanned for absorption at 538 $\mathrm{nm}$ (the observed absorbance maxima) and $700 \mathrm{~nm}$ using a Shimadzu 300 ultraviolet-vis spectrophotometer (Shimadzu). An extinction coefficient of 1700 corresponding to published values for petunidin 3-( $p$-coumaroyl-rutinoside)-5-glucoside was used (Price and Wrolstad, 1995). For the samples analyzed in 2006 (Table 1), extractions were diluted five-fold in $\mathrm{pH}$ buffers and absorbance was read at an observed absorbance maxima of $545 \mathrm{~nm}$ rather than at $538 \mathrm{~nm}$ like in 2004.

Carotenoid extraction. Carotenoids were extracted from tomatoes using a modified version of the method described by Ferruzzi et al. (2001). All the extractions were completed under gold lamps (Sylvania F40/GO; Osram Sylvania, Danvers, MA) to reduce light degradation. Six replicate samples were taken of five ripe tomato fruit that were homogenized in a blender for $2 \mathrm{~min}$. Ten grams of the resulting tomato purée was added to $1 \mathrm{~g}$ $\mathrm{CaCO}_{3}$ and $25 \mathrm{~mL}$ methanol in a glass vial with a Teflon-lined cap. Samples were vortexed for 2 min followed by centrifugation at $730 g_{\mathrm{n}}$ for $5 \mathrm{~min}$. The supernatant was collected in a separate sealed flask, and the juice solids were reextracted with

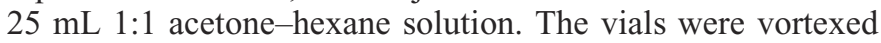
and centrifuged and supernatant added to the sealed flask. The tomato juice was extracted again with $25 \mathrm{~mL} \mathrm{1:1} \mathrm{acetone-}$ hexane but not centrifuged after the final extraction. The collected supernatant was vacuum-filtered through Whatman \#1 (Whatman International Ltd., Middlesex, UK) qualitative paper, and the remaining solid material in the vial was also vacuum-filtered into the same flask. The vial and supernatant

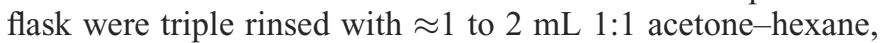
pouring the solutions into the vacuum flask. Filtrate was added to a separatory funnel together with $2 \% \mathrm{NaCl}$ solution and allowed to stand, sealed, for $20 \mathrm{~min}$. Next, the lower aqueous layer was decanted and the upper hexane layer saved. The hexane layer was placed in a $50-\mathrm{mL}$ flask with $1 \mathrm{~g} \mathrm{NaSO}_{4}$ to remove residual water. This solution was then pipetted into a 50-mL glass vial with a Teflon-lined cap. The $\mathrm{NaSO}_{4}$ mixture was triple rinsed with 1:1 acetone:hexane and the wash solution added to the glass vial. The solution was then dried under nitrogen in a water bath at $35^{\circ} \mathrm{C}$ and the contents sealed under nitrogen when dry. Ten milliliters of methylene chloride was added to the vial to dissolve the carotenoids as well as any other lipophilic compounds present. Two-milliliter samples of this solution were filtered through a $0.45-\mu \mathrm{m}$ polytetrafluoroethylene membrane Acrodisc filter (Waters) into an amber vial for carotenoid analysis by HPLC.

Determination of tomato Carotenoid Content. Two solvents were used for HPLC: solvent A was 70:30 acetonitrile:1-butanol and solvent B was 100\% methylene chloride. HPLC conditions were based on the method of Lin and Chen (2003). Briefly, conditions started at 99\% A for $1 \mathrm{~min}$, transitioning to $96 \%$ A over $20 \mathrm{~min}$, transitioning to $90 \%$ A over $30 \mathrm{~min}$, and transitioning to $88 \%$ A over $5 \mathrm{~min}$; linear gradients were used for all solvent transitions. A YMC Carotenoid S-5 $4.0 \times 20$-mm guard cartridge (Waters) was mated to a $\mathrm{YMC} \mathrm{C}_{30}$ carotenoid column, $250 \mathrm{~mm} \times 4.5 \mu \mathrm{m}$ (Waters). A Waters 996 PDA detector scanned between 250- and 550-nm wavelengths at $1.2-\mathrm{nm}$ intervals every $0.5 \mathrm{~s}$. All-trans-lycopene, all-trans- $\beta$ carotene, prolycopene, $\alpha$-carotene, $\delta$-carotene, $\zeta$-carotene, neurosporene, lutein, and $E / Z$-phytoene standards were purchased from CaroteNature (Lupsingen, Switzerland). Standards were dissolved in chloroform. Subsamples were diluted in hexane for purity testing using an ultraviolet-vis spectrophotometer. Absorption was measured and compared with published $\lambda$ max and extinction coefficients (Goodwin, 1976; Lin and Chen, 2003). Carotenoid identification was based on retention time and comparison of spectra with standards and with published values for carotenoids in the same or similar solvent systems.

Extraction efficiency was determined by repeated extractions of $r r$ genotype tomatoes. The yellow flesh tomatoes were ideal for determining extraction efficiency because exogenous carotenoids introduced into the extract other than $\beta$-carotene will not coelute with any endogenous carotenoids of the tomato. Standard solutions of lycopene and $\beta$-apo- $8^{\prime}$-carotenal were added to separate glass vials. The carrier solvent for these carotenoid standards was evaporated under nitrogen. Next, $r r$ tomato purée or juice was added to the vial for extraction and the vials were extracted using the previously described procedure. The calculated extraction efficiency using this method was $83.1 \%$ for lycopene and $85.0 \%$ for $\beta$-apo- $8^{\prime}$-carotenal. All carotenoid data presented in this report are the raw values and thus represent an underestimate of the carotenoids present.

Determination of total Phenolics. Total phenolics were determined using the Folin-Ciocalteu (F-C) method (Singleton and Rossi, 1965) from the ethyl acetate and methanol fractions produced in the anthocyanin extraction procedure. One-half milliliter of each of the sample fractions was added to $7.5 \mathrm{~mL}$ $\mathrm{ddH}_{2} \mathrm{O}$ with $0.5 \mathrm{~mL} \mathrm{F-C} \mathrm{reagent} \mathrm{and} \mathrm{allowed} \mathrm{to} \mathrm{stand} \mathrm{for} 10$ min. A total of $1.5 \mathrm{~mL} 20 \% \mathrm{Na}_{2} \mathrm{CO}_{3}$ solution was added and vials kept at $40{ }^{\circ} \mathrm{C}$ in a heat block for $20 \mathrm{~min}$. Vials were placed on ice and immediately measured for absorbance at $755 \mathrm{~nm}$ using a Shimadzu 300 ultraviolet-vis spectrophotometer. A standard curve was prepared using serial dilutions of gallic acid monohydrate (Sigma Chemical Co., St. Louis). The average of five reactions was used to determine the value of a single data point on one of three fruit used per replicate.

\section{Results and Discussion}

Phenotypic and genotypic Characterization. Anthocyanin levels in the skins of tomato fruit were lowest in the single gene lines and greatest where atv was combined with either $A f t$ 
or $A b g$. Pigment intensity followed a progression that can be seen in Figure 2 as follows: (Aft Aft atv atv) > LA3668 $(A b g) \approx$ LA1996 (Aft) > LA0797 (atv) > LA3736 (atv). The combination $A b g-A f t$ - (not shown) increases pigment intensity only slightly over the gene expressed singly, whereas the combination $A b g$ - atv atv shows a similar observable pigment intensity to the Aft-atv atv combination (Fig. 3). Double mutants of atv with either $A f t$ or $A b g$ can be distinguished by the presence of purple stems and leaves (a characteristic of atv) and the intensely pigmented fruit that results from the double gene combination. We have been unable to fix $A b g$ in either the original accession or in any of our breeding lines. Homozygous lines are completely sterile and fail to set fruit, thereby preventing the phenotype of $A b g$ to be expressed in homozygous condition.

Fruit with $A f t$ alone had a total anthocyanin content of 72.32 $\mathrm{mg} / 100 \mathrm{~g}$ fresh weight (FW) of skin in 2004 and ranged from 17.68 to $36.35 \mathrm{mg} / 100 \mathrm{~g} \mathrm{FW}$ in 2006 (Table 1). Aft in combination with atv or $h p-1$ significantly increased anthocyanin levels. Aft combined with $B$ had significantly lower levels of anthocyanin accumulation than Aft alone. The effect of $r$ when combined with $A f t$ and atv unexpectedly greatly reduced anthocyanin concentrations (Table 1). The $r$ allele produces a nonfunctional phytoene synthase, significantly reducing carotenoid production (Fray and Grierson, 1993). That $r$ reduces the anthocyanin response of the Aft atv combination suggests the possibility of a crosstalk relationship between the carotenoid and flavonoid pathways. This possibility has been previously considered unlikely (Long et al., 2006), because the $r r$ genotype results in changes in the profile but not in total phenylpropanoid and flavonoids. However, Minoggio et al. (2003) has reported similar inverse relationships between tomato polyphenols and carotenoids. Highest levels of anthocyanin accumulation were seen in fruit combining $A b g$ with atv and were almost fourfold higher than the Aft atv double mutant. It should be noted that these lines do not necessarily share the same genetic background, which may quantitatively influence anthocyanin accu-

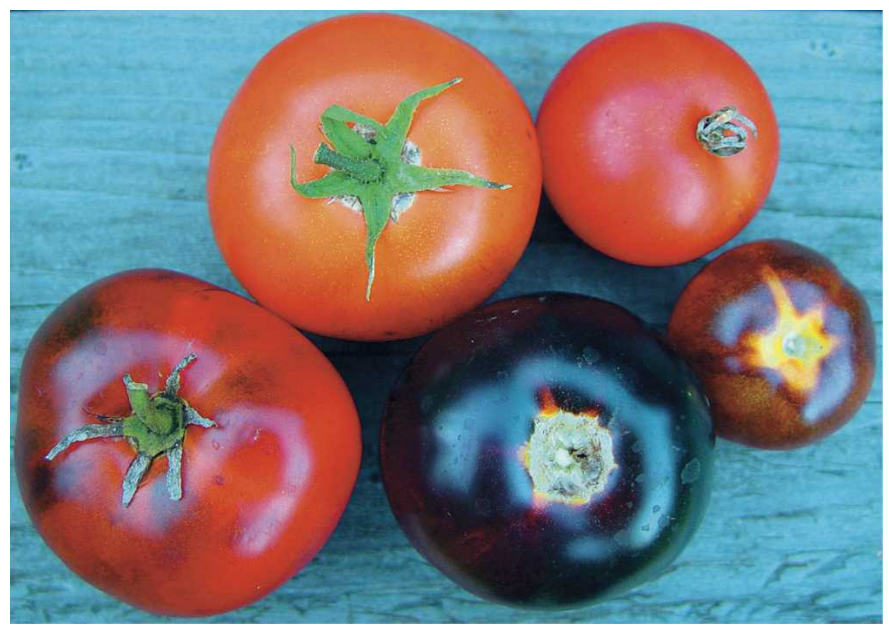

Fig. 2. Tomato fruit from genetic stocks accessions and breeding lines showing varying levels of anthocyanin expression. Clockwise from top: LA0797 (atv atv), LA3736 (atv atv), LA3668 (Abg-), OSU P20 (AftAft atvatv), and LA1996 (Aft Aft). LA lines were obtained form the C.M. Rick Tomato Genetic Stocks Collection, University of California, Davis and OSU P20 is a breeding line developed by the Oregon State University Vegetable Breeding and Genetics Program.
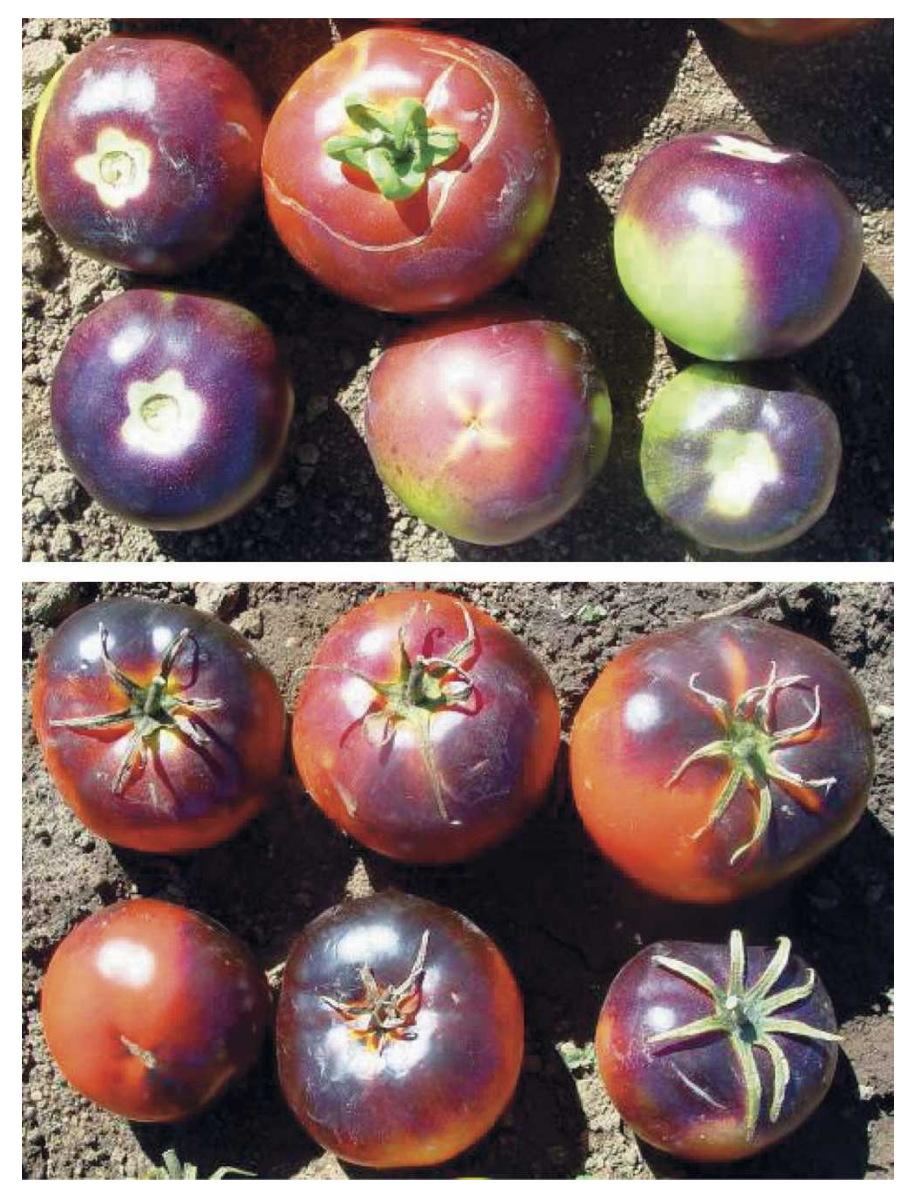

Fig. 3. Anthocyanin expression of tomato fruit gene combinations of LA0797 (atv atv) with LA3668 (Abg) (top) or LA1996 (Aft) (bottom) grown at the Vegetable Farm, Corvallis, OR, in 2004.

mulation. Furthermore, the difference in fruit size has been demonstrated to directly affect total anthocyanin (Mes, 2005), which may account for some of this difference.

Total polyphenols showed a concordant increase in lines carrying the anthocyanin genes. In lines that lacked anthocyanin genes, a mean of $160 \mathrm{mg} / 100 \mathrm{~g} \mathrm{FW}$ skin total gallic acid equivalents (GAE) was observed. GAE for the anthocyanin-containing lines were similar to or higher than the nonanthocyanincontaining lines and ranged up to $\approx 450 \mathrm{mg} / 100 \mathrm{~g} \mathrm{FW}$ skin total GAE. GAE was strongly and significantly correlated $\left(\mathrm{R}^{2}=\right.$ 0.78 ) with total anthocyanins on a milligram per $100 \mathrm{~g} \mathrm{FW}$ tomato skin basis (Fig. 4).

SPECTROPHOTOMETRIC CHARACTERIZATION OF FLAVONOIDS. The initial spectral scan of phenolics from a sample of $A f t A f t$ atvatv genotype tomato by transmission spectrophotometer showed major peaks at 311 and $549 \mathrm{~nm}$. The peak at $311 \mathrm{~nm}$ was the result of the presence of multiple, nonanthocyanin flavonoids. These are compounds that do not contribute significantly to absorption in the $500-\mathrm{nm}$ range but have strong absorption in the ultraviolet range. The $\lambda$-max peak at $549 \mathrm{~nm}$ is far higher than the expected $520 \mathrm{~nm}$ of the anthocyanidin petunidin and is evidence of acylation of the anthocyanins present in purple tomatoes.

Initial analysis of AftAft atvatv and Abg-atvatv by HPLC revealed near identical peak elution times and respective peak sizes. Without standards for comparison, the peaks were not 


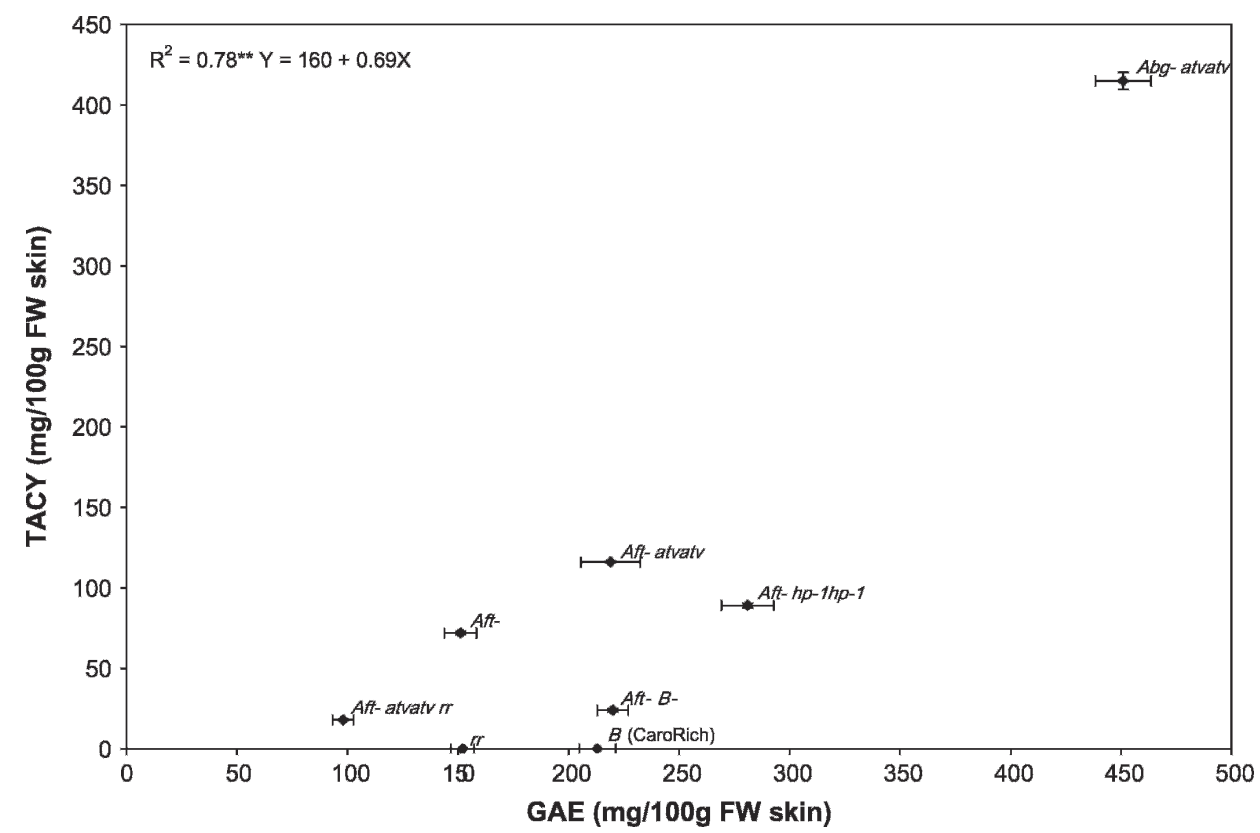

Fig. 4. Relationship between total phenolics [gallic acid equivalents (GAE)] and total anthocyanins (TACY) of different genotypes of anthocyanin containing tomato fruit. Error bars for $\mathrm{x}$ and $\mathrm{y}$ axes based on mean separation by Fisher's protected least significant difference in which $P \leq 0.05$.

Table 2. Anthocyanin composition in tomato fruit from plants with the genotype AftAft atvatv as detected by HPLC-MS.

\begin{tabular}{lccc}
\hline & \multicolumn{3}{c}{ Detected mass (m/z) } \\
\cline { 2 - 4 } Functional groups & Delphinidin & Petunidin & Malvidin \\
\hline Anthocyanidin & 303 & $317^{\mathrm{z}}$ & - \\
Glycoside & 465 & $479^{\mathrm{z}}$ & $493^{\mathrm{z}}$ \\
Rutinoside & 611 & - & $639^{\mathrm{z}}$ \\
p-coumaroyl + rutinoside & 757 & $771^{\mathrm{z}}$ & $785^{\mathrm{z}}$ \\
p-coumaroyl + rutinoside + glycoside & 919 & 933 & 947 \\
Caffeic acid + rutinoside & 773 & 787 & 801 \\
Caffeic acid + rutinoside + glycoside & 935 & 949 & 963 \\
p-coumaroyl + rutinoside + glycoside + glycoside & - & $1,095^{\mathrm{z}}$ & $1,109^{\mathrm{z}}$ \\
Caffeic acid + rutinoside + glycoside + glycoside & - & $1,111^{\mathrm{z}}$ & $1,125^{\mathrm{z}}$ \\
\hline
\end{tabular}

${ }^{\mathrm{z}}$ Only detected in trace quantities; - $=$ no detected mass.

HPLC-MS = high-performance liquid chromatography—mass spectroscopy.

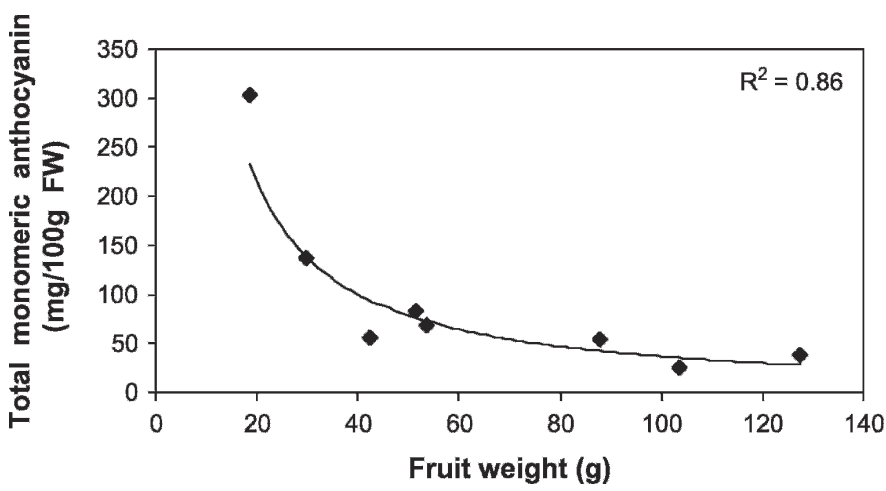

Fig. 5. Effect of fruit size on total anthocyanin content in tomato fruit with AftAft atvatv genotype.

positively identified. As a result of their similarity, only Aftatvatv genotype samples were used for subsequent analysis. A sample was hydrolyzed to remove the acyl- and glucosyl- moieties to simplify the chromatogram. Peak elution times of the hydrolyzed sample were compared with standards produced from hydrolyzed Welch's Concord Grape Juice (Welch Foods, Concord, MA). The results of the chromatogram from hydrolyzed tomato line were consistent with previous reports (Jones et al., 2003; Rao, 1978). The primary anthocyanidin in tomato fruit is petunidin, with malvidin and delphinidin also present based on comparisons of elution times to standards. The ratio of total petunidin : malvidin : delphinidin was estimated to be $78: 21: 1$ based on area under the peaks.

To determine the moieties attached to the anthocyanin, samples were injected into an HPLC-MS system, allowing spectral analysis followed by mass determination. In preparation for this, a sample was saponified and analyzed by HPLC to estimate the anthocyanin glycoside moieties to predict which masses to expect. The peak elution times were consistent with that of a diglycoside. For this reason, MS scans were made up to $1100 \mathrm{mass} / \mathrm{charge}(\mathrm{m} / \mathrm{z})$, because most diglycosides have an $\mathrm{m} / \mathrm{z}$ of 600 to 700 and single acyl moieties add between 90 and $160 \mathrm{~m} / \mathrm{z}$. Parent peaks were identified at 933, 947, $919,625,632$, and $611 \mathrm{~m} / \mathrm{z}$ with daughter peaks at 331, 317, and 303 $\mathrm{m} / \mathrm{z}$. A subsequent direct injection MS-electron scan detected these peaks as well as several others in lesser quantities (Table 2). These masses were compared with all combinations of known anthocyanidins and glycosyl and acyl moieties. The predominant acylated anthocyanin was the peak at $933 \mathrm{~m} / \mathrm{z}$, consistent with petunidin-3-(p-coumaryl)-rutinoside-5glucoside. The most predominant nonacylated anthocyanin was the peak at $611 \mathrm{~m} / \mathrm{z}$, consistent with delphinidin-3-rutinoside. Based on the HPLC-MS relative peak intensities, delphinidin was the dominant anthocyanidin. However, peak intensities do not necessarily correspond to sample concentration resulting from differences in ionization. More reliable quantitative data came from the HPLC of the hydrolyzed anthocyanins, indicating that petunidin was the predominant anthocyanidin.

Anthocyanin Quantification. The previously published value in $A f t$ fruit was 20 to $60 \mathrm{mg} / 100 \mathrm{~g} \mathrm{FW}$ (Jones et al., 2003). The genotypes tested varied widely in visually observed pigment expression and in fruit size with the highest observed anthocyanin expression of AftAft atvatv fruit grown in the greenhouse in Spring 2004 of 300 mg/100 g FW. Fruit size and observable anthocyanin had significant effect on total measurable monomeric anthocyanins. Figure 5 reveals an 
Table 3. Carotenoid content of fresh tomatoes with selected combinations of carotenoid and anthocyanin mutants grown at the Vegetable Farm in Corvallis, OR, in 2004.

\begin{tabular}{|c|c|c|c|c|c|c|c|c|}
\hline \multirow[b]{2}{*}{ Carotenoid } & \multicolumn{8}{|c|}{ Genotype $^{z}$} \\
\hline & Normal & Aft- & Aft-atvatv & $r r$ & Aft-rr & $B B$ & $A f t-B-$ & Aft- hp-1hp-1 \\
\hline & \multicolumn{8}{|c|}{ ug.g ${ }^{-1} \mathrm{FW}$} \\
\hline Trans-lutein +9 -cis lutein & 0.45 & 0.49 & 0.49 & 0.52 & 0.45 & 0.57 & 0.49 & 0.55 \\
\hline Phytoene, E/Z & 6.40 & 6.61 & 4.79 & & & 6.52 & 4.90 & 9.42 \\
\hline Phytofluene & 3.40 & 3.83 & 2.65 & & & 2.66 & 2.48 & 6.86 \\
\hline Unknown 1 & & & & & & 0.57 & & \\
\hline 9-cis-beta-carotene & 1.14 & & & & & & 1.92 & \\
\hline Zeta carotene & 0.69 & 0.54 & 0.50 & & & 6.44 & 0.59 & 0.70 \\
\hline Beta-carotene & 7.68 & 4.63 & 3.96 & 0.24 & 0.18 & 24.51 & 21.10 & 16.58 \\
\hline Unknown 2 & & & & & & 2.67 & & 0.77 \\
\hline cis-beta-carotene & 0.38 & 0.17 & & & & 2.94 & 0.61 & \\
\hline 15-cis-lycopene & & 1.08 & 0.67 & & & & & 0.65 \\
\hline cis-delta-carotene? & & & & & & 0.15 & & \\
\hline Unknown 7 & & 5.14 & & & & 2.12 & & \\
\hline 13-cis-lycopene? & & 0.93 & 2.93 & & & 0.72 & 0.61 & 1.34 \\
\hline Unknown 9 & & & & & & 1.09 & & \\
\hline 9, 13-di cis-lycopene & 4.13 & 1.96 & 0.72 & & & 1.24 & 2.30 & 2.76 \\
\hline Unknown 11 & 0.68 & 1.96 & & & & 1.66 & 1.10 & \\
\hline 9-cis-lycopene & 0.63 & 0.79 & 0.56 & & & 1.06 & & \\
\hline 5-cis-lycopene & 1.71 & & & & & 0.76 & & \\
\hline All-trans lycopene & 24.00 & 32.88 & 15.48 & & & 8.72 & 11.43 & 55.63 \\
\hline Total & 51.29 & 61.00 & 32.74 & 0.77 & 0.63 & 64.58 & 47.53 & 95.26 \\
\hline
\end{tabular}

${ }^{\mathrm{z}}$ Normal $=$ Legend; $B B=$ CaroRich; origins of other genotypes are shown in Table 1.

$\mathrm{FW}=$ fresh weight.

inverse-logarithmic relationship between total anthocyanin content and fruit weight for skin extractions. The data points are the result of multiple extractions of greenhouse-grown Aftatvatv genotype fruit of varying sizes. The inverse relationship between fruit size and total monomeric anthocyanin content is the result of the regulation of anthocyanin expression. Light incidence is a requirement for anthocyanin expression. In smaller fruit, more skin tends to be exposed to light, and there is less self-shading. Large and small fruit on the same plant exhibited this difference: small fruit have anthocyanin expressed well beneath the "equator," approaching the blossom end, whereas large fruit would not express anthocyanin below the equator. This results in a greater fraction of the skin expressing anthocyanin in smaller fruit. Thus, skins from smaller tomatoes have higher total anthocyanins than do larger tomatoes. For this reason, maximizing anthocyanin expression without genetic change in the anthocyanin biosynthetic or regulatory pathways requires that fruit size must be minimized and light incidence maximized. It also is important to report fruit size together with anthocyanin content because the two are not independent of each other.

INTERACTION OF FLAVONOIDS AND CAROTENOIDS. Although certain carotenoid genotypes affected levels of anthocyanin accumulation, particularly $r$ and $B$ (Table 1; Fig. 4), the reverse did not hold true. Carotenoid levels of Aft-, Aft-atv atv, and $A b g$ - lines were similar to the nonanthocyanin-expressing type with the main difference in carotenoids being attributable to the introduction of genes that affect the carotenoid pathway $(r, B$, and $h p-1$; Table 3 ). Thus, it appears that the carotenoids may affect some degree of interaction with the flavonoid pathway, whereas the flavonoid pathway has little or no effect on the carotenoid pathway.

\section{Conclusions}

$A b g, A f t$, and atv produce fruit with elevated anthocyanin content. Combining atv with Aft or Abg produces an anthocyanin response elevated beyond that observed in any of the three genes by themselves. Increasing fruit size diminishes the total anthocyanin content. Further increases in anthocyanin content may be accomplished through the combination of the anthocyanin-affecting genes with selection for smaller fruit size. The anthocyanin and anthocyanidin profile of the fruit is complex but appears to be consistent among genotypes, evidence that neither $A f t$ nor $A b g$ are structural genes within the biochemical pathway producing anthocyanins.

\section{Literature Cited}

Boches, P. and J.R. Myers. 2007. The anthocyanin fruit tomato gene $(A f t)$ is associated with a DNA polymorphism in a MYB transcription factor. HortScience 42:856 (abstr.).

Butler, L. 1962. Muddy fruit, a phenotype of the gene gf. Tomato Genet. Coop. Rpt. 12:19.

Canady, M.A., J. Yuanfu, and R.T. Chetelat. 2006. Homeologous recombination in Solanum lycopersicoides introgression lines of cultivated tomato. Genetics 174:1775-1788.

DeJong, W.S., N.T. Eannetta, D.M. DeJong, and M. Bodis. 2004. Candidate gene analysis of anthocyanin pigmentation loci in the Solanaceae. Theor. Appl. Genet. 108:423-432.

Durst, R.W. and R.E. Wrolstad. 2001. Separation and characterization of anthocyanins by HPLC, Unit F1.3.1-13. In: Wrolstad, R.E. (ed.). Current protocols in analytical chemistry. Wiley, New York.

Ferruzzi, M.G., M.L. Nguyen, L.C. Sander, C.L. Rock, and S.J. Schwartz. 2001. Analysis of lycopene geometrical isomers in biological microsamples by liquid chromatography with coulometric array detection. J. Chromatography B 760:289-299. 
Fray, R.G. and D. Grierson. 1993. Identification and genetic analysis of normal and mutant phytoene synthase genes of tomato by sequencing, complementation and co-suppression. Plant Mol. Biol. 22:589-602.

Georgiev, C. 1972. Anthocyanin fruit (Af). Tomato Genet. Coop. Rpt. 22:10.

Goodwin, T.W. 1976. Chemistry and biochemistry of plant pigments. Academic Press, New York.

Guisti, M.M. and R.E. Wrolstad. 2001. Anthocyanins. Characterization and measurement with UV-visible spectroscopy, Unit F1.2.113. In: Wrolstad, R.E. (ed.). Current protocols in food analytical chemistry. Wiley, New York.

Ibrahim, H., S. Shannon, and R.W. Robinson. 1968. Influence of the high pigment gene on anthocyanin content. Tomato Genet. Coop. Rpt. 18:21.

Jones, C.M. 2000. Evaluation of carotenoids and anthocyanins in high pigment, processing, heirloom, and anthocyanin fruit tomatoes, Oregon State University, Corvallis, MS Thesis.

Jones, C.M., P. Mes, and J.R. Myers. 2003. Characterization and identification of the anthocyanin fruit (Aft) tomato. J. Hered. 94:449_ 456.

Kendrick, R.E., L.H.J. Kerckhoffs, A.S. Pundsnes, A. Van Tuinen, M. Koornneef, A. Nagatani, M.J. Terry, A. Tretyn, M. Cordonnier-Pratt, B. Hauser, and L.H. Pratt. 1994. Photomorphogenic mutants of tomato. Euphytica 79:227-234.

Kerckhoffs, L.H.J., N.A.M.A. De Groot, A. Van Tuinen, M.E.L. Schreuder, A. Nagatini, M. Koornneef, and R.E. Kendrick. 1997. Physiological characterization of exaggerated-photoresponse mutants of tomato. J. Plant Physiol. 150:578-587.

Kerr, E.A. 1956. Green flesh, gf. Tomato Genet. Coop. Rpt. 6:17.

Krause, M. and R. Galensa. 1992. Determination of naringenin and baringenin-chalcone in tomato skins by reverse phase HPLC after solid-phase extraction. Z. Lebensm. Unters. Forsch. 194:29-32.

Lin, C.H. and B.H. Chen. 2003. Determination of carotenoids in tomato juice by liquid chromatography. J. Chromatogr. A. 1012:103-109.

Liu, Y., S. Roof, Z. Ye, C. Barry, A. Van Tuinen, J. Vrebalov, C. Bowler, and J. Giovannoni. 2004. Manipulation of light signal transduction as a means of modifying fruit nutritional quality in tomato. Proc. Natl. Acad. Sci. USA 101:9897-9902.

Long, M., D.J. Millar, Y. Kimura, G. Donovan, J. Rees, P.D. Fraser, P.M. Bramley, and G.P. Bolwell. 2006. Metabolite profiling of carotenoid and phenolic pathways in mutant and transgenic lines of tomato: Identification of a high antioxidant fruit line. Phytochemistry 67:1750-1757.

Mes, P.J. 2005. Breeding tomatoes for improved antioxidant activity. Oregon State University, Corvallis, PhD Diss.

Minoggio, M., L. Bramati, P. Simonetti, C. Gardana, L. Iemoli, E. Santagelo, P.L. Mauri, P. Spigno, G.P. Soressi, and P.G. Pietta. 2003. Polyphenol pattern and antioxidant activity of different tomato lines and cultivars. Ann. Nutr. Metab. 47:64-69.

Muir, S.R., G.J. Collins, S. Robinson, S. Hughes, A. Bovy, C.H.R. De Vos, A.J. Van Tunen, and M.E. Verhoeyen. 2001. Over-expression of petunia chalcone isomerase in tomato results in fruit containing increased levels of flavonols. Nat. Biotechnol. 19:470-474.

Price, C.L. and R.E. Wrolstad. 1995. Anthocyanin pigments of Royal Okanogan huckleberry juice. J. Food Sci. 60:369-374.

Rao, G.R. 1978. Role of fruit pigments in understanding the interrelationship and mechanism of evolution of higher chromosomal forms of the species of the Solanum nigrum L. complex. Acta Bot. Indica. 6(Suppl.):41-47.

Rick, C.M. 1964. Biosystematic studies on Galápagos tomatoes. Occasional Papers California Acad. Sci. 44:59-71.

Rick, C.M. 1980. Tomato, p. 669-680. In: Fehr, W.R. and H. Hadley (eds.). Hybridization of crop plants. Amer. Soc. Agron., Crop Sci. Soc. Amer., Madison, WI.

Rick, C.M., P. Cisneros, R.T. Chetelat, and J.W. DeVerna. 1994. AbgA gene on chromosome 10 for purple fruit derived from $\mathrm{S}$. lycopersicoides. Tomato Genet. Coop. Rpt. 44:29-30.

Rick, C.M., A.F. Reeves, and R.W. Zobel. 1968. Inheritance and linkage relations of four new mutants. Tomato Genetics Coop. Rpt. 18:34-35.

Rodriguez-Saona, L.E. and R.E. Wrolstad. 2001. Anthocyanins. Extraction, isolation and purification of anthocyanins, Unit F.1.1.1-11. In: Wrolstad, R.E. (ed.). Current protocols in food analytical chemistry. Wiley, New York.

Singleton, V.L. and J.L. Rossi. 1965. Colorimetry of total phenolics with phosphomolybdicphosphotungstic acid reagents. Amer. J. Enol. Viticult. 16:144-158.

Verhoeyen, M.E., A. Bovy, G. Collins, S. Muir, S. Robinson, C.H.R. de Vos, and S. Colliver. 2002. Increasing antioxidant levels in tomato through modification of the flavonoid biosynthetic pathway. J. Expt. Bot. 53:2099-2106. 